\title{
Power System Frequency Response From the Control of Bitumen Tanks
}

\author{
Meng Cheng, Jianzhong Wu, Member, IEEE, Stephen J. Galsworthy, Carlos E. Ugalde-Loo, Member, IEEE, \\ Nikola Gargov, William W. Hung, and Nick Jenkins, Fellow, IEEE
}

\begin{abstract}
Bitumen tanks were tested to investigate the capability of industrial heating loads to provide frequency response to an electric power system. A decentralized control algorithm was developed enabling the tanks to alter their power consumption in proportion to the variations of grid frequency. The control maintains the normal operation of tanks and causes little impact on their primary function of storing hot bitumen. Field investigations were undertaken on 76 tanks with power ratings from 17 to $75 \mathrm{~kW}$. A model of a population of controlled tanks was developed. The behavior of the tanks was compared between the simulations and the field tests. The model of controlled tanks was then integrated with a simplified Great Britain power system model. It was shown that the controlled tanks were able to contribute to the grid frequency control in a manner similar to and faster than that provided by frequency-sensitive generation.
\end{abstract}

Index Terms-Demand response, dynamic control, electric power system, frequency response, industrial bitumen tanks, smart grid.

\section{INTRODUCTION}

F REQUENCY indicates the balance between generation and demand in a power system on a second-by-second basis. In the Great Britain (GB) power system, the steady state limits of frequency are $50 \pm 1 \% \mathrm{~Hz}$ [1]. Conventionally, control of frequency is mainly achieved by scheduling sufficient frequency-sensitive generators. The GB Grid Code [2] requires that all large generating stations, power park modules, and HVDC interconnectors should be capable of providing frequency response services. Following a loss of generation, primary response halts the frequency fall in $10 \mathrm{~s}$ and lasts for another $20 \mathrm{~s}$. Secondary response is fully available in $30 \mathrm{~s}$

Manuscript received July 25, 2014; revised February 05, 2015; accepted May 18, 2015. Date of publication June 19, 2015; date of current version April 15, 2016. This work was supported in part by Open Energi, London, U.K., the National Grid NIA Project, and the RCUK-EPSRC under Projects EP/K006274/1 and EP/L014351/1 . Paper no. TPWRS-01012-2014.

M. Cheng, J. Wu, C. E. Ugalde-Loo, and N. Jenkins are with the Institute of Energy, School of Engineering, Cardiff University, Cardiff CF 24 3AA, U.K. (e-mail: ChengM2@cardiff.ac.uk; WuJ5@cardiff.ac.uk; JenkinsN6@cardiff.ac.uk; Ugalde-LooC@cardiff.ac.uk).

S. J. Galsworthy is with Open Energi, London EC4A 3BG, U.K., and also with TNO, The Hague 2595 DA, The Netherlands (e-mail: Stephen.Galsworthy@openenergi.com).

N. Gargov is with National Grid, Warwick CV34 6DA, U.K. (e-mail: Nikola. Gargov@nationalgrid.com).

W. W. Hung is with WH Power System Consultant Ltd., Leamington Spa CV32 6PJ U.K. (e-mail: ukwilliamhung@gmail.com).

Color versions of one or more of the figures in this paper are available online at $\mathrm{http}: / /$ ieeexplore.ieee.org.

Digital Object Identifier 10.1109/TPWRS.2015.2440336 and is sustained for $30 \mathrm{~min}$ to restore frequency. For a loss of demand, high frequency response limits the frequency rise within $10 \mathrm{~s}$ and then restores frequency to $50 \mathrm{~Hz}$.

Balancing generation and demand in the GB power system will become more difficult as the generation mix changes towards 2020 [3]. Integration of renewable energy sources that are connected by power electronic converters will reduce inertia of the power system and so changes in frequency will become more rapid. Thus, a faster frequency response is needed to compensate for this reduction of inertia. For an "abnormal loss" of generation up to $1320 \mathrm{MW}$ (which has been increased to $1800 \mathrm{MW}$ from April 2014), the maximum drop in frequency should not be greater than $0.8 \mathrm{~Hz}$ and should be restored to $49.5 \mathrm{~Hz}$ within $1 \mathrm{~min}$. It will be costly to use partly loaded conventional generators to provide frequency response. The cost of holding frequency response in the GB power system was estimated to be $£ 160$ million per year based on the price of frequency response in 2009 [4].

Demand is an alternative means of managing grid frequency. Present operational practice of the GB power system allows demand, mainly the contracted large industrial loads such as steelworks [5], to be disconnected automatically by a low-frequency relay typically set at $49.7 \mathrm{~Hz}$. If the frequency continues to drop below $48.8 \mathrm{~Hz}$, as an emergency measure, demand on the public distribution networks will be disconnected automatically at stages to prevent shutdown of the power system [2]. Such load shedding is activated only for a large frequency fall and requires manual reconnections after the frequency recovery.

Time-flexible demand is not critical as to when the electrical energy is consumed [6]. Thus, power consumption of such demand is able to be time-shifted. The work in [7] developed a grid-friendly control to shift power consumption of domestic appliances during the peak-demand period. The direct control of thermostatically controlled loads such as water heaters to provide regulating services according to signals sent by the system operator was developed in [8] and [9]. The feasibility of using time-flexible loads to assist or even replace spinning reserves was discussed in [10]. Dynamic response from domestic loads such as refrigerators to provide frequency response was investigated in [11] and [12]. The general idea of these papers was to allow the pre-set temperature range of loads to vary with the deviation of frequency. If frequency drops, the temperature set-points of refrigerators will be increased and the refrigerators are switched off earlier.

However, there are still challenges for demand response, as discussed in [13] - especially that demand control reduces the diversity of loads. The lack of load diversity may cause the loads 


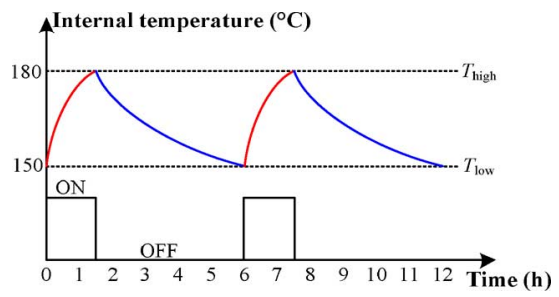

Fig. 1. Conventional temperature control of one bitumen tank.

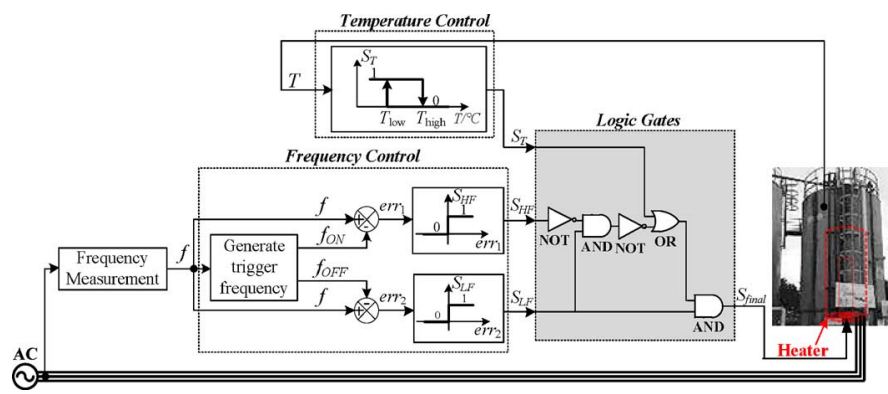

Fig. 2. Local control scheme of one bitumen tank.

to be switched again simultaneously after the provision of frequency response. This will cause a second disturbance of grid frequency. In addition, variations of temperature set-points of thermal loads may cause the internal temperature of a load to be outside its normal range.

\section{Control of Bitumen Tanks}

\section{A. Temperature Control of Bitumen Tanks}

Liquid bitumen is stored in large, well-insulated tanks. A heater uses a hysteresis control shown in Fig. 1 to maintain the temperature in the tank within a low set-point ( $T_{\text {low }}$, typically $\left.150{ }^{\circ} \mathrm{C}\right)$ and a high set-point $\left(T_{\text {high }}\right.$, typically $\left.180^{\circ} \mathrm{C}\right)$. Change of the ON/OFF state of a heater occurs if temperature in the tank reaches $T_{\text {low }}$ or $T_{\text {high }}$. A tank has a typical power consumption of $40 \mathrm{~kW}$ when its heater is $\mathrm{ON}$.

\section{B. Use of Bitumen Tanks for Grid Frequency Control}

An additional controller was added to the conventional temperature control as shown in Fig. 2. The frequency control of each tank measures the grid frequency $(f)$ and generates state signals $\left(S_{\mathrm{HF}}\right.$ and $\left.S_{\mathrm{LF}}\right)$ by comparing $f$ with two trigger frequencies $\left(f_{\mathrm{ON}}\right.$ and $\left.f_{\mathrm{OFF}}\right)$. If $f$ is above $f_{\mathrm{ON}}, S_{\mathrm{HF}}$ is 1 . The tank will be triggered $\mathrm{ON}$ by the frequency rise. If $f$ is below $f_{\mathrm{OFF}}, S_{\mathrm{LF}}$ is 0 . The tank will then be triggered OFF by the frequency drop.

Initially, $f_{\mathrm{ON}}$ and $f_{\mathrm{OFF}}$ are generated randomly using a uniform distribution within a given range. $f_{\mathrm{ON}}$ is in the range of $50-50.5 \mathrm{~Hz}$ and $f_{\mathrm{OFF}} 49.5-50 \mathrm{~Hz}$. The trigger frequencies determine the sequence in which tanks are switched. Following a frequency rise, tanks are switched ON starting from the one which has an $f_{\mathrm{ON}}$ closest to $50 \mathrm{~Hz}$. Conversely, following a frequency drop, tanks are switched OFF starting from the one which has an $f_{\mathrm{OFF}}$ closest to $50 \mathrm{~Hz}$. The more the frequency deviates from $50 \mathrm{~Hz}$, the more tanks respond.
TABLE I

Truth TABLE OF Logic GATES OF FIG. 2

\begin{tabular}{ccccc}
\hline \hline Row & $S_{T}$ & $S_{H F}$ & $S_{L F}$ & $S_{\text {final }}$ \\
\hline 1 & 0 & 1 & 1 & 1 \\
2 & 1 & 1 & 1 & 1 \\
3 & 0 & 0 & 0 & 0 \\
4 & 1 & 0 & 0 & 0 \\
5 & 0 & 0 & 1 & 0 \\
6 & 1 & 0 & 1 & 1 \\
7 & 0 & 1 & 0 & 0 \\
8 & 1 & 1 & 0 & 0 \\
\hline \hline
\end{tabular}

\section{Integrated Control}

The integrated control scheme for both temperature and grid frequency control is also shown in Fig. 2. The temperature control measures the temperature $(T)$ of a tank and generates state signals $\left(S_{T}\right)$. The frequency control measures the grid frequency $(f)$ and generates state signals $\left(S_{\mathrm{HF}}\right.$ and $\left.S_{\mathrm{LF}}\right)$. The final switching signal $\left(S_{\text {final }}\right)$ to the heater is then determined by the state signals $S_{\mathrm{HF}}, S_{\mathrm{LF}}$ and $S_{T}$ according to Table I. "1" represents the "ON-state" and "0" represents the "OFF-state."

For a rise in frequency, if $f$ rises higher than $f_{\mathrm{ON}}$, then $S_{\mathrm{HF}}$ is 1 and $S_{\mathrm{LF}}$ is 1 as shown in rows $1-2$ of Table I. The tank is then switched ON $\left(S_{\text {final }}=1\right)$.

Conversely, for a drop in frequency, if $f$ drops lower than $f_{\mathrm{OFF}}$, the tank is switched OFF $\left(S_{\mathrm{LF}}=0\right.$ in rows 3-4 of Table I and $S_{\text {final }}=0$ ).

If $f$ is between $f_{\mathrm{ON}}$ and $f_{\mathrm{OFF}}$, the tank follows the temperature control $\left(f_{\mathrm{ON}}>f>f_{\mathrm{OFF}}\right.$ gives $S_{\mathrm{HF}}=0$ and $S_{L F}=1$ in rows 5-6 of Table I and $S_{\text {final }}=S_{T}$ ).

Rows 7-8 of Table I are not feasible states because $f$ cannot be lower than $f_{\text {OFF }}$ and higher than $f_{\text {ON }}$ simultaneously.

To avoid frequent switching actions which may damage the heater, a minimum ON/OFF time of around $25 \mathrm{~s}$ is applied to each tank.

\section{Update of $f_{\mathrm{OFF}}$ and $f_{\mathrm{ON}}$}

$f_{O F F}$ and $f_{\mathrm{ON}}$ are updated based on measurements of the present frequency $f(t)$ and the previous frequency sample $f(t-$ $\Delta t)$. The sampling time interval $(\Delta t)$ of measuring the grid frequency $f$ was $200 \mathrm{~ms}$.

To illustrate the reason of updating $f_{\mathrm{OFF}}$, three tanks are chosen as examples as shown in Fig. 3. In Fig. 3(a), $f_{\mathrm{OFF}}$ remains unchanged, while in Fig. 3(b) $f_{\mathrm{OFF}}$ is updated with $f$.

Conventional control of a load in response to frequency is shown in Fig. 3(a). Tank 1 has $f_{\mathrm{OFF} 1}$ at $49.9 \mathrm{~Hz}$, Tank 2 has $f_{\mathrm{OFF} 2}$ at $49.8 \mathrm{~Hz}$, and Tank 3 has $f_{\mathrm{OFF} 3}$ at $49.6 \mathrm{~Hz}$. When $f$ drops, Tank 1 is switched OFF followed by Tank 2 . When $f$ starts to recover and rises towards $50 \mathrm{~Hz}$, Tank 2 reverts back ON at $t_{2}$ followed by Tank 1 at $t_{1}$. This implies that Tank 1 , which was the first to be switched OFF, is reconnected last. Moreover, Tank 3 is not switched at all since $f_{\mathrm{OFF} 3}$ remains lower than $f$. Tank 1 is without energy for a long time while Tank 3 provides no response to the frequency drop. The frequency response from the three tanks is uneven. Tanks with a lower $f_{\mathrm{OFF}}$ provide reduced frequency response.

The dynamic load control shown in Fig. 3(b) was implemented in order to maintain an even distribution of switch requests amongst all tanks. $f_{\mathrm{OFF}}$ is updated with the recovery of $f$ following the rules listed in Table II. 

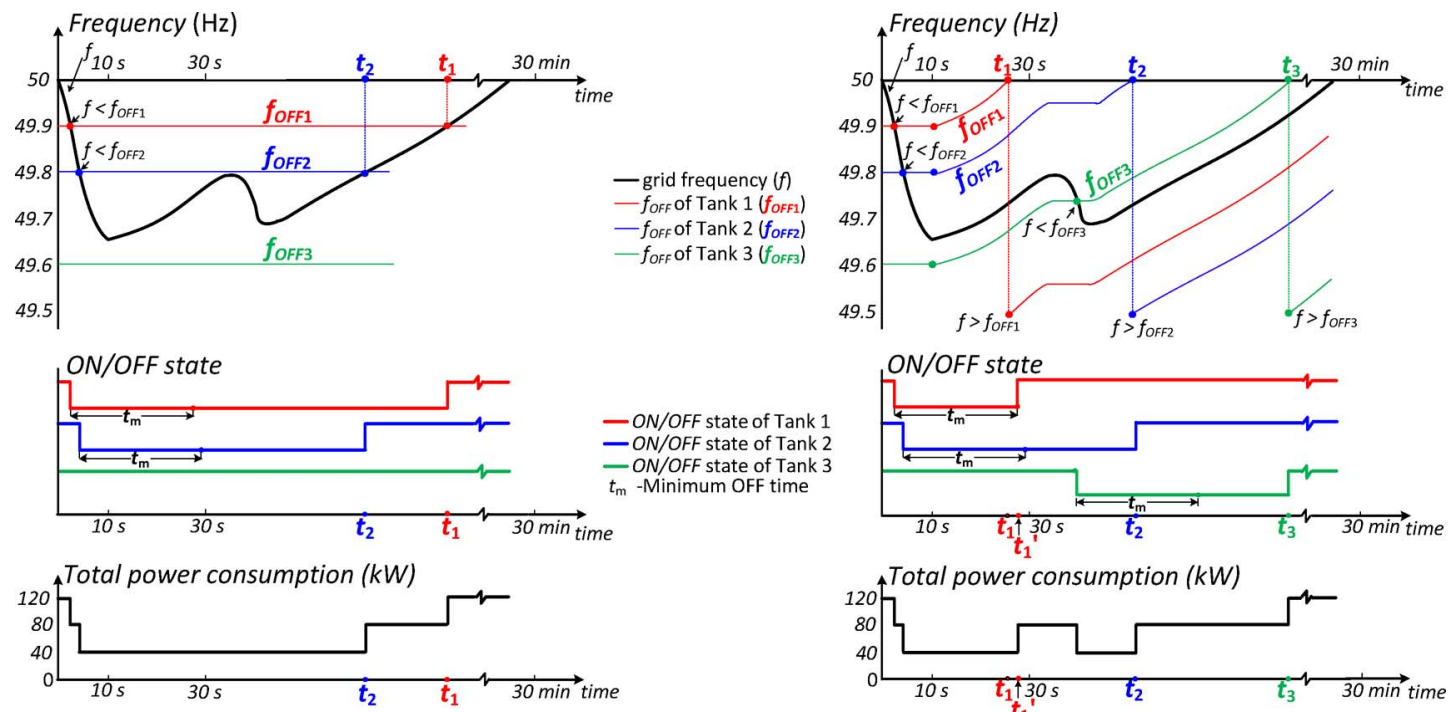

(a)

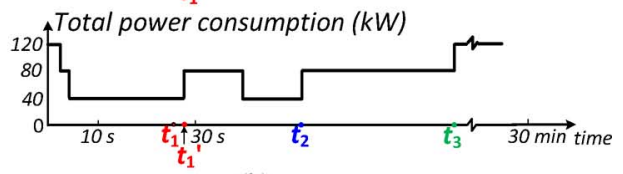

(b)

Fig. 3. Dynamic update of trigger frequency $f_{\mathrm{OFF}}$ of three tanks during a drop of frequency. (a) Conventional direct load control with constant $f_{\mathrm{OFF}}$. (b) Dynamic load control with varying $f_{\mathrm{OFF}}$.

TABLE II

UPDATE OF TRIGGER FREQUENCY $f_{\text {OFF }}$

\begin{tabular}{|c|c|c|}
\hline \multicolumn{2}{|c|}{ Variation of Frequency $f$} & Update of $f_{O F F}$ \\
\hline \multicolumn{2}{|c|}{$f \geq 50 \mathrm{~Hz}$} & $f_{\text {OFF }}(t)=f_{\text {OFF }}(t-\Delta t)(1)$ \\
\hline \multirow[b]{2}{*}{$f<50 \mathrm{~Hz}$} & $\begin{array}{l}f \text { drops or is } \\
\text { constant: } \\
f(t) \leq f(t-\Delta t)\end{array}$ & $f_{O F F}(t)=f_{O F F}(t-\Delta t)(2)$ \\
\hline & $\begin{array}{l}\text { frises: } \\
f f(t)>f(t-\Delta t)\end{array}$ & $\begin{array}{l}f_{\text {OFF }}(t)=f_{\text {OFF }}(t-\Delta t)+f(t)-f(t-\Delta t) \\
\text { (3) } \\
\text { If } f_{\text {OFF }}(t) \text { reaches } 50 \mathrm{~Hz}: \\
f_{\text {OFF }}(t)=f_{\text {OFF }}(t)-0.5 \mathrm{~Hz} \text { (4) }\end{array}$ \\
\hline
\end{tabular}

- When $f$ is above $50 \mathrm{~Hz}, f_{\text {OFF }}$ remains unchanged (1).

- When $f$ is dropping or constant below $50 \mathrm{~Hz}, f_{O F F}$ remains unchanged (2).

- When $f$ is rising but is below $50 \mathrm{~Hz}, f_{\text {OFF }}$ is updated towards $50 \mathrm{~Hz}$ by adding the variations of $f$ given by (3). If $f_{\mathrm{OFF}}$ reaches $50 \mathrm{~Hz}, f_{\mathrm{OFF}}$ is then reset to $49.5 \mathrm{~Hz}$ by subtracting $0.5 \mathrm{~Hz}(4)$. This makes $f_{\mathrm{OFF}}$ the lowest trigger frequency. $f$ is then greater than $f_{\mathrm{OFF}}$ which triggers the tank to revert back ON.

The effect of such update is shown in Fig. 3(b). Tank 1 is the first to be switched ON because $f_{\mathrm{OFF} 1}$ reaches $50 \mathrm{~Hz}$ first and is re-set to $49.5 \mathrm{~Hz}$ at $t_{1}$. Tank 1 is switched $\mathrm{ON}$ at $t_{1}^{\prime}$ instead of $t_{1}$ due to the minimum OFF-time $\left(t_{\mathrm{m}}\right)$ of $25 \mathrm{~s}$. Comparing the OFF-time of Tank 1 to that in Fig. 3(a), the loss of energy to Tank 1 is reduced significantly.

Tank 2 is switched ON at $t_{2}$. Its OFF-time is also shorter than that in Fig. 3(a).

Tank 3 has a low initial $f_{\mathrm{OFF}}$ and was not switched OFF at the first drop of $f$. However, when the second frequency drop occurs, Tank 3 is switched OFF as $f_{\mathrm{OFF} 3}$ has been updated to be greater than $f$. Tank 3 is then reconnected at $t_{3}$. Compared to Fig. 3(a), Tank 3 provides additional frequency response.

By updating $f_{\mathrm{OFF}}$, the response of tanks is made more sensitive to the variations of grid frequency. This is shown by comparing the curve of total power consumption in Fig. 3(b) to that in Fig. 3(a). The tanks are controlled to recover starting from
TABLE III

UPDATE OF TRIGGER FREQUENCY $f_{\text {ON }}$

\begin{tabular}{|c|c|c|}
\hline \multicolumn{2}{|c|}{ Variation of Frequency $f$} & Update of $f_{O N}$ \\
\hline \multicolumn{2}{|l|}{$f \leq 50 \mathrm{~Hz}$} & $f_{O N}(t)=f_{O N}(t-\Delta t)(5)$ \\
\hline \multirow[b]{2}{*}{$f>50 \mathrm{~Hz}$} & $\begin{array}{l}\text { frises or is } \\
\text { constant: } \\
f(t) \geq f(t-\Delta t)\end{array}$ & $f_{O N}(t)=f_{O N}(t-\Delta t)(6)$ \\
\hline & $\begin{array}{l}f \text { drops: } \\
f(t)<f(t-\Delta t)\end{array}$ & $\begin{array}{l}f_{O N}(t)=f_{O N}(t-\Delta t)+f(t)-f(t-\Delta t) \\
(7) \\
\text { If } f_{O N}(t) \text { reaches } 50 \mathrm{~Hz}: \\
f_{O N}(t)=f_{O N}(t)+0.5 \mathrm{~Hz}(8)\end{array}$ \\
\hline
\end{tabular}

the one that was the first to be disconnected. All tanks have an equal opportunity to provide frequency response and the shift of their heating cycle is minimized.

The trigger frequency $f_{\mathrm{ON}}$ is updated using a similar method which follows the rules listed in Table III.

The dynamic control method presented in Section II-D provides a novel way to control the power consumption of tanks in response to frequency deviations by continuously updating the trigger frequencies, which gives equal opportunity to tanks to respond to frequency events. This method allows the aggregated demand to provide frequency response in a manner similar to the droop control of conventional large generators and hence enables the quantification of the amount of frequency response from demand. The uncertainty in demand response is also reduced.

\section{Modeling of Bitumen TANKS AND the GB POWER SYSTEM}

\section{A. Modeling of Bitumen Tanks}

The heat transfer process of a tank is shown in Fig. 4(a). Its heat supply rate $P_{\text {supply }}(\mathrm{W})$ and heat loss rate $P_{\text {loss }}(\mathrm{W})$ are

$$
\begin{aligned}
P_{\text {supply }} & =P \times S_{\mathrm{h}} \\
P_{\text {loss }} & =U \times A \times\left(T-T_{\mathrm{Amb}}\right)
\end{aligned}
$$




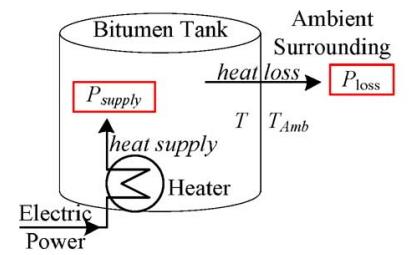

(a)

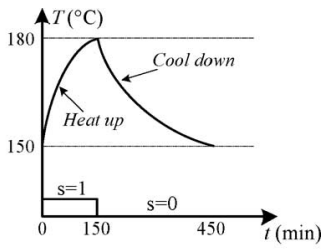

(b)
Fig. 4. Heat transfer and temperature of a bitumen tank with an ON period of $150 \mathrm{~min}$ and OFF period of $300 \mathrm{~min}$. (a) Heat transfer process of a bitumen tank. (b) Internal temperature of a bitumen tank with the ON period of $150 \mathrm{~min}$ and OFF period of $300 \mathrm{~min}$.

where $P(\mathrm{~W})$ is the power consumption of the heater, $S_{\mathrm{h}}$ is the heater state $\left(S_{\mathrm{h}}=1\right.$ if heater is ON and $S_{\mathrm{h}}=0$ if heater is OFF), $U\left(\mathrm{Wm}^{-2} \mathrm{~K}^{-1}\right)$ is the overall heat transfer coefficient, $A$ $\left(\mathrm{m}^{2}\right)$ is the area of the tank, $T(\mathrm{~K})$ is the internal temperature of the tank and $T_{\mathrm{Amb}}(\mathrm{K})$ is the outside temperature.

The net rate of heat transfer $P_{\text {net }}(\mathrm{W})$ is

$$
P_{\text {net }}=P_{\text {supply }}-P_{\text {loss }} \text {. }
$$

Heat transfer results in a change of temperature $\mathrm{d} T(\mathrm{~K})$ inside the tank. The relationship between the net rate of heat transfer and the rate of internal temperature changes is

$$
P_{\text {net }}=c_{\mathrm{v}} \times m \times \frac{\mathrm{d} T}{\mathrm{~d} t}
$$

where $c_{\mathrm{v}}\left(\mathrm{Jkg}^{-1} \mathrm{~K}^{-1}\right)$ is the specific heat capacity of the tank and $m(\mathrm{~kg})$ is the mass.

Equations (9)-(12) are combined to obtain a first-order differential equation for the internal temperature $T$

$$
\frac{\mathrm{d} T}{\mathrm{~d} t}=\frac{P \times S_{\mathrm{h}}}{c_{\mathrm{v}} \times m}-\frac{U \times A \times\left(T-T_{\mathrm{Amb}}\right)}{c_{\mathrm{v}} \times m} .
$$

Equation (13) has two possible solutions depending on the heater state $S_{\mathrm{h}}$. For instance, for a tank with an ON-period of $150 \mathrm{~min}$ and OFF-period of $300 \mathrm{~min}$ as given in Fig. 4(b), the two solutions of (13) for its internal temperature are

$$
\begin{gathered}
S_{\mathrm{h}}=1: T(t)=184.68-34.68 \times e^{-t / 74.91}, \\
0 \leq t<150 \mathrm{~min} \\
S_{\mathrm{h}}=0: T(t)=145.32+34.68 \times e^{-(t-150) / 149.81}, \\
150 \leq t<450 \mathrm{~min} .
\end{gathered}
$$

A thermodynamic model of the tank was developed using (14) and (15).

Fig. 5(a) shows the heating and cooling of a tank. The tank is switched $\mathrm{ON}$ at its low set-point $\mathrm{B}$ and its temperature follows the curve BC. Conversely, the tank is switched OFF at $\mathrm{C}$ and follows the curve CD. However, a tank may be switched $\mathrm{ON} / \mathrm{OFF}$ at an intermediate temperature. In Fig. 5(a) the tank heater is $\mathrm{ON}$ at Point $\mathrm{A}$. If the heater remains $\mathrm{ON}$, the temperature will follow the curve $\mathrm{AC}$ for a time $t_{\mathrm{ON}}$ until $T_{\text {high }}$ is reached at $\mathrm{C}$. Alternatively, if the heater is switched OFF at $\mathrm{A}$, the temperature will follow the curve AE. $t_{O F F}$ is defined as the time for the temperature to reach $T_{\text {low }}$ at $\mathrm{E}$. A similar process occurs when a tank is initially OFF at point $\mathrm{F}$ as shown in Fig. 5(b).

The minimum value of $t_{\mathrm{ON}}$ is zero and occurs when the temperature reaches $T_{\text {high }}$. The maximum value of $t_{\mathrm{ON}}$ is the total ON-state period $\tau_{\mathrm{ON}}$ when the temperature reaches $T_{\mathrm{low}}$. Similarly, the range of $t_{\mathrm{OFF}}$ is from zero to $\tau_{\mathrm{OFF}}$.

Based on Fig. 5, for a tank with known ON and OFF periods, a pair of $t_{\mathrm{ON}}$ and $t_{\mathrm{OFF}}$ are calculated for different temperatures $T$ using the inverse functions of (14) and (15). For each $T$, the calculated pair of $t_{\mathrm{ON}}$ and $t_{\mathrm{OFF}}$ is plotted by a cross in Fig. 6(a). Using the curve fitting function "cftool" in MATLAB, a semicircle relationship of $t_{\mathrm{ON}}$ and $t_{\mathrm{OFF}}$ is obtained. The analytical expression is shown in

$$
\begin{aligned}
t_{\mathrm{ON}} & =\tau_{\mathrm{ON}} \times \sqrt{1-\left(\frac{t_{\mathrm{OFF}}}{\tau_{\mathrm{OFF}}}\right)^{2}} \\
t_{\mathrm{OFF}} & =\tau_{\mathrm{OFF}} \times \sqrt{1-\left(\frac{t_{\mathrm{ON}}}{\tau_{\mathrm{ON}}}\right)^{2}} .
\end{aligned}
$$

$t_{\text {ON }}$ and $t_{\text {OFF }}$ were measured on two $40-\mathrm{kW}$ and two $25-\mathrm{kW}$ real tanks at different times of a day. Test results were used to validate the thermodynamic model through the relationship in (16) and (17). At different temperatures of one tank, a pair of $t_{\mathrm{ON}}$ and $t_{\mathrm{OFF}}$ was measured by recording the time of the tank to remain $\mathrm{ON}$ and remain $\mathrm{OFF}$. The measured $t_{\mathrm{ON}}$ and $t_{\mathrm{OFF}}$ at each temperature were then depicted by a cross in Fig. 6(b) in which the measurements of a $40-\mathrm{kW}$ tank is shown. The relationships in (16) and (17) were confirmed by the field measurements in Fig. 6(b). By comparing Fig. 6(a) and (b), it is clear that the relationship of $t_{\mathrm{ON}}$ and $t_{\mathrm{OFF}}$, shown in (16) and (17), matches closely with both the thermodynamic model and the field measurements.

A simplified curve-fit model was also developed. The variation of the internal temperature with time was modeled directly through the variations of $t_{\mathrm{ON}}$ and $t_{\mathrm{OFF}}$ as shown in Table IV for all possible thermal states. $\Delta t$ is the time step. Equation (19) was obtained based on (17) and (20) was based on (16).

Simulations using the thermodynamic model based on (14) and (15) and the curve-fit model based on equations in Table IV were undertaken in MATLAB/Simulink. Both models simulated the normal operating cycle of 500 tanks over 10 $\mathrm{h}$ with a simulation time step of $1 \mathrm{~s}$. In the thermodynamic model, a different initial temperature was assigned to each tank by randomizing the starting time in (14) and (15) in order to reflect the diversity amongst tanks. In the curve-fit model, the initial $t_{\mathrm{ON}}$ in Table IV was assigned randomly in the range of 0 to $\tau_{\mathrm{ON}}$ and $t_{\mathrm{OFF}}$ in the range of 0 to $\tau_{\mathrm{OFF}}$. The value of $\tau_{\mathrm{ON}}$ was distributed randomly within its measured range of $42-180 \mathrm{~min}$ and $\tau_{\mathrm{OFF}}$ within its measured range of 60-480 min. Table V shows a comparison of the actual time it took to run the simulation with each model.

The curve-fit model shows a faster computational speed than the thermodynamic model. Therefore, the curve-fit model was used for the studies in this paper.

The simplified curve-fit model of tanks is able to reflect the thermodynamics of a tank accurately. The modelling method avoids the acquisition of physical parameters such as the heat 


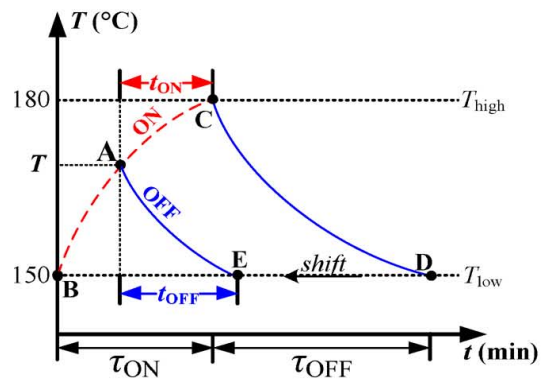

a)

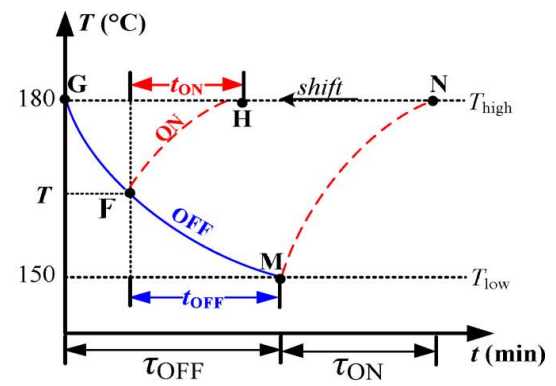

b)

Fig. 5. Diagram of $t_{\mathrm{ON}}$ and $t_{\mathrm{OFF}}$ at any temperature of a bitumen tank. (a) Heating and cooling of a bitumen tank at ON state. (b) Heating and cooling of a bitumen tank at OFF state.

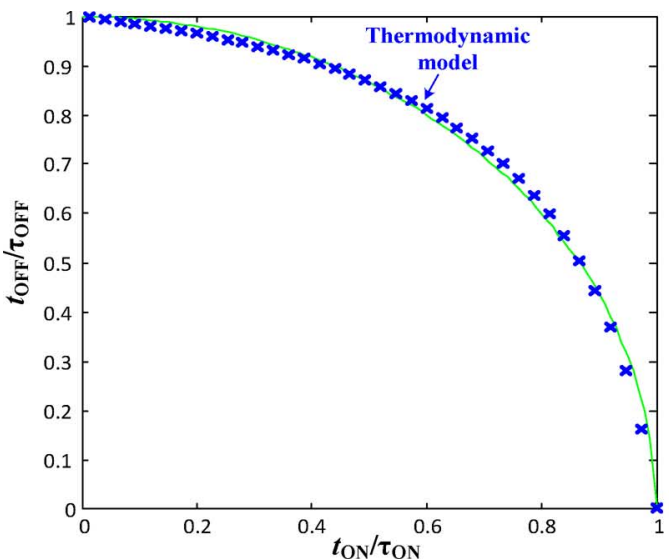

(a)

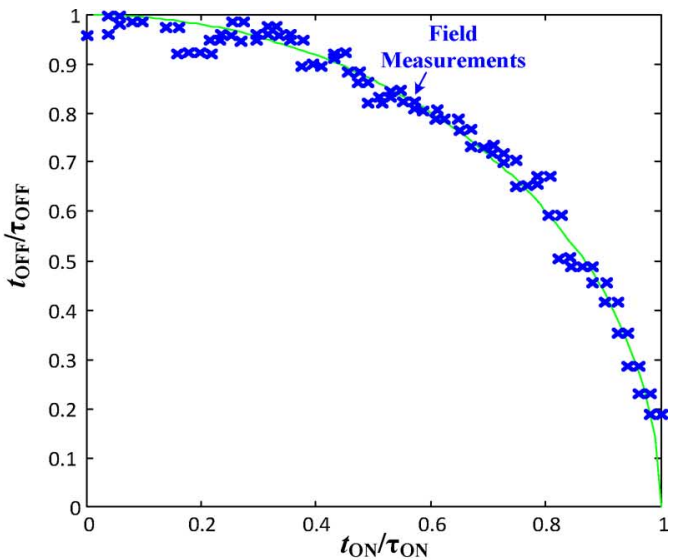

(b)

Fig. 6. Relationship of $t_{\mathrm{ON}}$ and $t_{\mathrm{OFF}}$ of a bitumen tank ( $t_{\mathrm{ON}}$ is normalized with $\tau_{\mathrm{ON}}$ and $t_{\mathrm{OFF}}$ is normalized with $\tau_{O F F}$ ). (a) $t_{\mathrm{ON}}$ and $t_{O F F}$ calculated using the thermodynamic model (14) and (15). (b) $t_{\mathrm{ON}}$ and $t_{\mathrm{OFF}}$ of field measurements.

TABLE IV

$t_{\text {ON }}$ AND $t_{\text {OFF }}$ OF THE CURVE-FIT MODEL

\begin{tabular}{c|c|c}
\hline \hline Heater State & Corresponding Curve in Fig. 5 & Variation of $t_{\mathrm{ON}}$ and $t_{\mathrm{OFF}}$ \\
\hline Remain ON at $t$ & $\mathrm{AC}$ & \multirow{2}{*}{$\begin{array}{c}t_{\text {ON }}(t+\Delta t)=t_{\text {ON }}(t)-\Delta t(18) \\
t_{\text {OFF }}(t+\Delta t)=\tau_{\text {OFF }} \times \sqrt{1-\left[\left(t_{\text {ON }}(t)-\Delta t\right) / \tau_{\text {ON }}\right]^{2}}(19)\end{array}$} \\
\hline Switched ON at $t$ & $\mathrm{FH}$ & $t_{\text {ON }}(t+\Delta t)=\tau_{\text {ON }} \times \sqrt{1-\left[\left(t_{\text {OFF }}(t)-\Delta t\right) / \tau_{\text {OFF }}\right]^{2}}(20)$ \\
Remain OFF at $t$ & $\mathrm{FM}$ & $t_{\text {OFF }}(t+\Delta t)=t_{\text {OFF }}(t)-\Delta t(21)$ \\
\hline Switched OFF at $t$ & $\mathrm{AE}$ &
\end{tabular}

coefficient, thermal mass and size of tanks. The only information required is the ON/OFF period of the tanks which is easily obtained through field measurements. The method can be applied to the modelling of other load types for which thermodynamic models are otherwise essential.

\section{B. Simplified GB Power System Model}

A simplified GB power system model for the study of power system frequency response was developed based on [14], [15] and is shown in Fig. 7.

The inertia constant of the power system $H_{\text {eq }}$ was $6.5 \mathrm{~s}$. It was estimated based on a frequency incident which occurred on September 30, 2012 [16]. A failure of an interconnector caused a loss of approximately $1000 \mathrm{MW}$ of generation. System demand at the time of incident was $33702 \mathrm{MW}$. The effect of frequencydependent loads in the power system is lumped into a damping constant $D$ which was set at $1.0 \mathrm{pu}[15]$.

The GB Grid Code requires all generators to have governor droop settings of $3 \%-5 \%$ [2] for the provision of primary response. Depending on the system demand level, some generators are also required to provide secondary response instructed by the system operator. Therefore, the generation system was modeled by two lumped generators (G1, G2). G1 represents generators that provide only primary response while $\mathrm{G} 2$ represents generators that provide both primary and secondary response. In the model shown in Fig. 7, $K$ was set to 0.8 indicating that $80 \%$ of generators provide secondary response.

The model of G1 includes a governor deadband $( \pm 15 \mathrm{mHz}$ [2]). The governor droop for the primary response is represented by a gain of $1 / R_{\text {eq }}$. The time constant of the governor 
TABLE V

Computational Speed of the Thermodynamic Model and the Curve-Fit Model for Simulating the Normal Operating Cycle of 500 TanKs OVER $10 \mathrm{H}$

\begin{tabular}{ccccc}
\hline \hline Model & Number of Tanks & Simulation Time & Time Step & Computer Running Time \\
\hline Thermodynamic Model & 500 & $10 \mathrm{~h}$ & $1 \mathrm{~s}$ & $5.5 \mathrm{~min}$ \\
Curve-fit Model & 500 & $10 \mathrm{~h}$ & $1 \mathrm{~s}$ & $3.6 \mathrm{~min}$ \\
\hline \hline
\end{tabular}

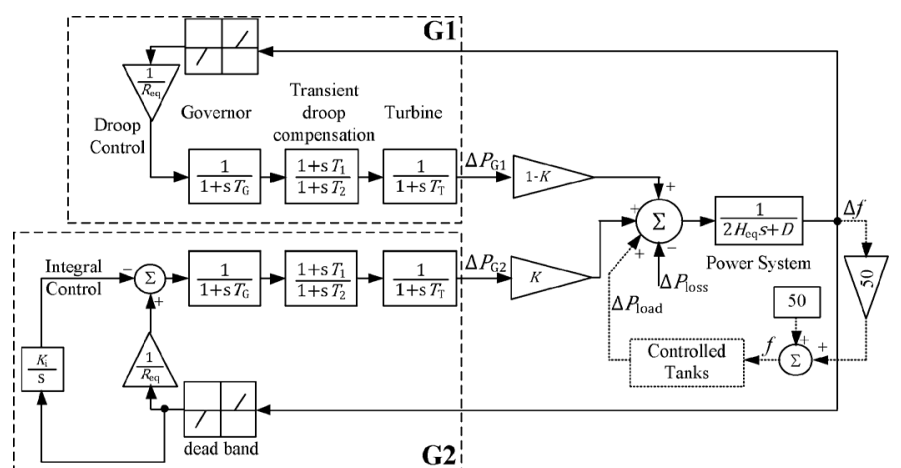

Fig. 7. Simplified GB power system model.

TABLE VI

Parameters of G1 and G2 In the Simplified Power System Model (SYSTEM BASE WAS 33702 MW)

\begin{tabular}{ccccccc}
\hline \hline DeadBand $(\mathrm{pu})$ & $R_{\mathrm{eq}}(\mathrm{pu})$ & $T_{\mathrm{G}}(\mathrm{s})$ & $T_{1}(\mathrm{~s})$ & $T_{2}(\mathrm{~s})$ & $T_{\mathrm{T}}(\mathrm{s})$ & $K_{\mathrm{i}}(\mathrm{pu})$ \\
\hline \pm 0.0003 & 0.05 & 0.2 & 2 & 20 & 0.3 & 0.05 \\
\hline \hline
\end{tabular}

is $T_{\mathrm{G}}$. For stable performance of the frequency control, a transient droop compensator with time constants $T_{1}$ and $T_{2}$ is placed [15]. The mechanical power is generated considering the turbine time constant $T_{T}$. All of the parameters used in Fig. 7 are shown in Table VI.

The model of G2 is similar to that of G1. However, to model its provision of secondary response, an extra integral control loop was added to restore the grid frequency to $50 \mathrm{~Hz}$.

\section{Field Tests on Tanks During Large Frequency DISTURBANCES}

A series of field tests were undertaken in July 2013 by Open Energi, a commercial aggregator providing demand response services to the GB system operator. The tests were carried out on 76 tanks with power ratings from 17 to $75 \mathrm{~kW}$. Each tank was equipped with the dynamic load control that is described in Section II. For the tests, the power system frequency input of the tank controllers was replaced by two profiles of power system frequency. One profile represented a frequency rise to $50.5 \mathrm{~Hz}$, with the other standing for a frequency drop to $49.2 \mathrm{~Hz}$. The profiles were applied 15 times. The power consumption of the 76 tanks was measured during 15 frequency injections and aggregated to obtain the frequency response for a population of 1140 tanks $(15 \times 76)$. The test results are shown in Figs. 8 and 9 for the frequency rise and in Figs. 10 and 11 for the frequency drop.

The tank model presented in Section III-A was used to simulate the field tests. The two frequency profiles were applied to an aggregated simulation model of 1140 tanks. The aggregated

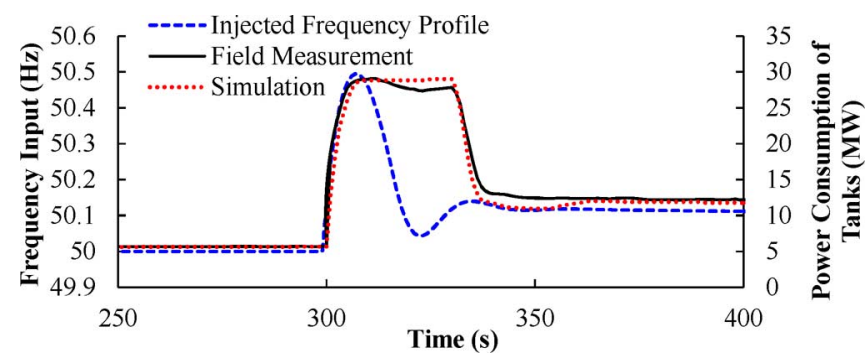

Fig. 8. Response of the 1140 tanks to the frequency rise.

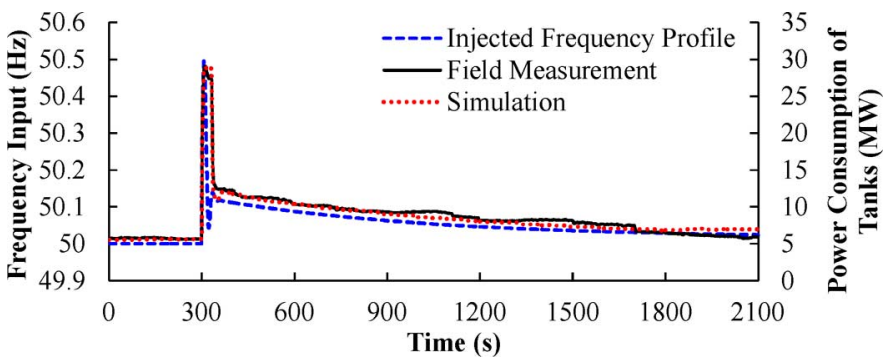

Fig. 9. Response of the 1140 tanks 30 min after the frequency rise.

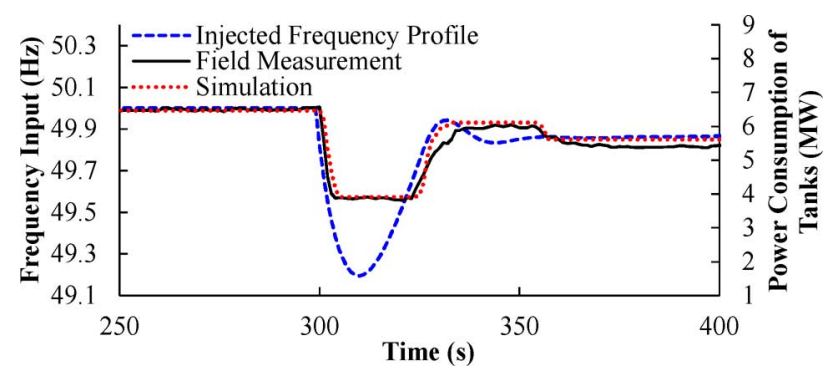

Fig. 10. Response of the 1140 tanks to the frequency drop.

power consumption of the modeled tanks was compared with that of the tested tanks as shown in Figs. 8-11.

As can be seen, the simulation and field test results show a similar power consumption of tanks upon frequency disturbances. The slight mismatches were caused by different initial states of the tested and the modeled tanks and the randomization of $f_{\mathrm{ON}}$ and $f_{\mathrm{OFF}}$ in their frequency controller.

Fig. 8 shows that the power consumption of tanks increased immediately following the frequency rise. The delay of tanks to be switched measured in the field tests was $0.7 \mathrm{~s}$. This is faster than the governor response of generators (fully delivered in 5-10 s). After the frequency rise, tanks reverted back to the previous OFF state following the recovery of frequency as shown in Fig. 9. Fig. 10 shows that some tanks with ON state were switched OFF during the frequency drop. After the frequency drop, tanks reverted back $\mathrm{ON}$ following the frequency recovery as shown in Fig. 11. 


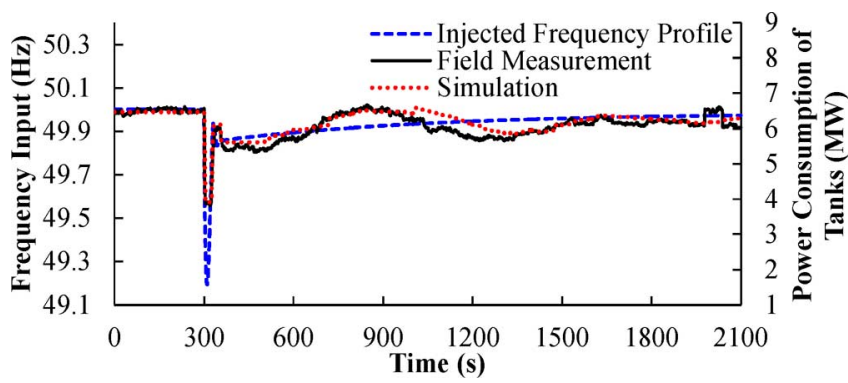

Fig. 11. Response of the 1140 tanks 30 min after the frequency drop.

Most low-frequency tests were carried out at around 2 AM. Some tank owners increased the low-temperature set-point of their tanks to maintain the internal temperature at a high level overnight in order to take advantage of the low electricity price (a low electricity tariff is available during British Summer Time 1:30 AM - 8:30 AM). However, each tank has a maximum number of switching events allowed per hour to avoid frequent switching actions which may damage the heater. This maximum number was determined in consultation with tank owners and typically lies in the range of four to ten switching events per hour. The manually increased low temperature set-points overnight caused these tanks to be switched ON and OFF more frequently and hence reached the maximum number of switching events. Such tanks were unavailable for low frequency response during the field test. This can be seen in Fig. 10 that power consumption of some tanks did not drop to zero when the frequency dropped to $49.2 \mathrm{~Hz}$.

Power consumption of the tanks was below the pre-event level all of the time when frequency was lower than $50 \mathrm{~Hz}$. At around $800 \mathrm{~s}$, the power consumption returned to the pre-event level. As a result of increasing the low-temperature set-point set by tank owners overnight, a number of tanks were switched ON. Therefore, after the frequency drop, these tanks were switched ON whilst the price of electricity was still low.

At any given time of day, the temperature of a tank is determined by its usage, which is different amongst a population of tanks. The inherent thermodynamics of a tank indicates that tank temperature keeps varying with time and hence the ON/OFF state. Therefore, it is unlikely that all tanks are heated up to the maximum temperature at the same time. Following a frequency event, the dynamic control method presented in Section II facilitates the maintenance of the diversity of tank temperature and ON/OFF state. Therefore, a consistent level of frequency response is usually available. However, for continuously repetitive and severe frequency incidents, the response from tanks may be reduced due to their temperature constraints.

The availability of tanks to provide frequency response at different times of day was measured through field investigations carried out by Open Energi as reported in [16]. Approximately $20 \%$ of tanks are able to provide low-frequency response during the night, and $5 \%$ of tanks are able to provide low-frequency response during the day.

\section{Case Studies on the GB Power System}

Case studies were undertaken considering 5000 tanks connected to the GB power system. The tank model is shown in

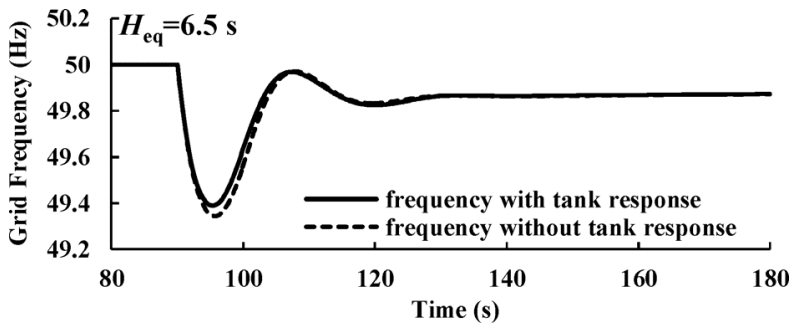

Fig. 12. Variation of grid frequency with $H_{\mathrm{eq}}$ of $6.5 \mathrm{~s}$.

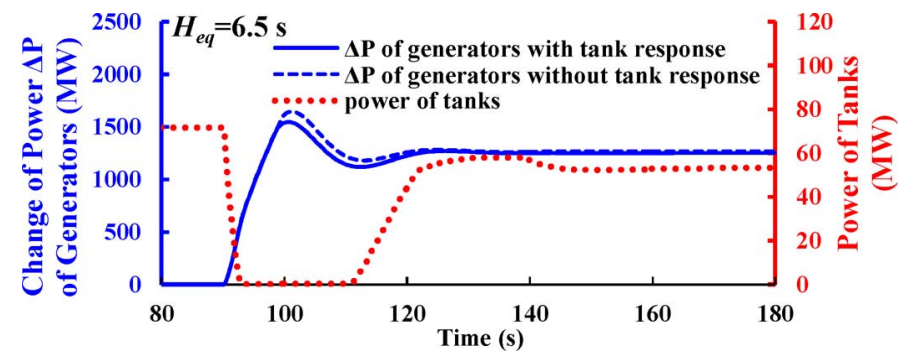

Fig. 13. Change of power output $(\Delta \mathrm{P})$ of generators and power consumption of tanks with $H_{\text {eq }}$ of $6.5 \mathrm{~s}$.

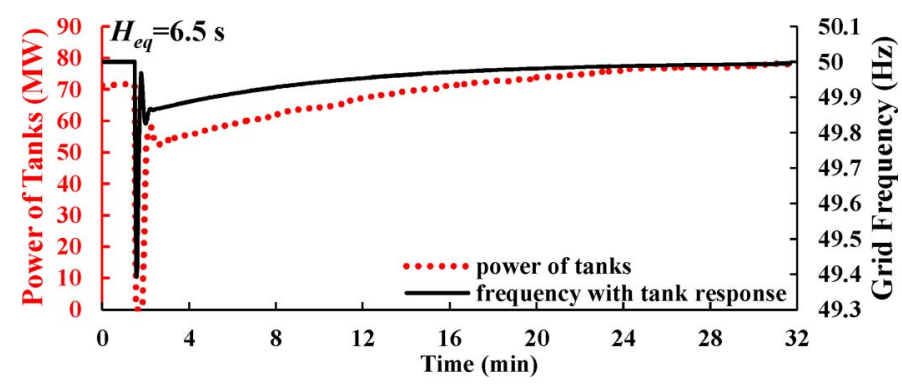

Fig. 14. Power consumption of tanks 30 min after the frequency drop with $H_{\text {eq }}$ of $6.5 \mathrm{~s}$.

Section III-A. Each tank model was equipped with the dynamic load control that is described in Section II. The power consumption of each tank was $40 \mathrm{~kW}$. The GB power system model is given in Fig. 7.

\section{A. First Case Study}

The first case study was carried out at a low system demand of $20 \mathrm{GW}$ representing a summer night. The system inertia used was $6.5 \mathrm{~s}$ when considering the current GB power system and $3.1 \mathrm{~s}$ to represent a future power system with much generation and load connected through inverters [17].

A loss of $1320 \mathrm{MW}$ of generation was applied to the model at $90 \mathrm{~s}\left(\Delta P_{\text {loss }}=0.066 \mathrm{pu}\right.$ in Fig. 7). The simulation results are shown in Figs. 12-15.

Figs. 12-14 show simulation results with the system inertia $6.5 \mathrm{~s}$. Fig. 12 shows the frequency after the loss of generation. Fig. 13 shows the change of power output of generators (see the left axis) and the power consumption of tanks (see the right axis). It can be seen the power consumption of tanks reduced almost immediately following the frequency drop. Because the simulation started at $0 \mathrm{~s}$ and ended at $30 \mathrm{~min}$, the maximum number of switching events per hour was not reached. Therefore, the power consumption of the tanks dropped to zero as 


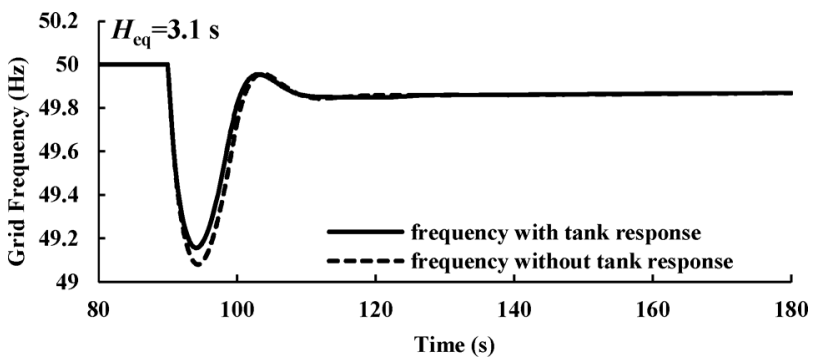

Fig. 15. Variation of grid frequency with $H_{\text {eq }}$ of $3.1 \mathrm{~s}$.

TABLE VII

Parameters of GB Model for the Second Case Study(System Base WAS $41 \mathrm{GW}$ )

\begin{tabular}{c|c|c|c|c|c|c|c|c|c}
\hline \hline $\begin{array}{c}\text { DeadBan } \\
\mathrm{d}(\mathrm{pu})\end{array}$ & $\begin{array}{c}R_{\mathrm{eq}} \\
(\mathrm{pu}\end{array}$ & $\begin{array}{c}T_{\mathrm{G}} \\
(\mathrm{s})\end{array}$ & $\begin{array}{c}T_{1} \\
(\mathrm{~s}\end{array}$ & $\begin{array}{c}T_{2} \\
(\mathrm{~s}\end{array}$ & $\begin{array}{c}T_{\mathrm{T}}(\mathrm{s} \\
)\end{array}$ & $\begin{array}{c}K(\mathrm{pu} \\
)\end{array}$ & $\begin{array}{c}K_{\mathrm{i}}(\mathrm{pu} \\
)\end{array}$ & $\begin{array}{c}H_{\mathrm{eq}} \\
(\mathrm{pu}\end{array}$ & $\begin{array}{c}D \\
(\mathrm{pu}\end{array}$ \\
\hline \pm 0.0003 & 0.5 & $\begin{array}{c}0 . \\
2\end{array}$ & 8 & 20 & 0.3 & 0.8 & 0.006 & 6.5 & 1 \\
\hline \hline
\end{tabular}

shown in Fig. 13. With the change of load of $72 \mathrm{MW}$ from the 5000 tanks, the maximum drop of grid frequency reduced $0.05 \mathrm{~Hz}$ (from 49.34 to $49.39 \mathrm{~Hz}$ ). The increase in the power output of generators was also reduced.

When the frequency started to recover, the tanks that had been disconnected were not reconnected immediately. These tanks remained OFF for the minimum OFF-time of around $25 \mathrm{~s}$ before they were reconnected. Fig. 14 shows the increase in the power of tanks (see the left axis) following the rise of frequency (see the right axis) during the recovery of frequency.

Fig. 15 shows the drop of frequency with the system inertia $3.1 \mathrm{~s}$. With the change of tank power from the 5000 tanks, the maximum drop of frequency reduced $0.08 \mathrm{~Hz}$ (from 49.08 to $49.16 \mathrm{~Hz})$.

\section{B. Second Case Study}

The second case study was carried out considering a multiple loss of generators. The case study was based on a severe frequency incident that occurred in the GB power system on May 28th 2008 [4]. The event was mainly caused by the unrelated consecutive loss of two generators (345 MW and $1237 \mathrm{MW}$ ) within $2 \mathrm{~min}$. The system demand at that time was $41 \mathrm{GW}$.

To obtain a frequency profile similar to that of the loss of the two generators in the incident, the parameters of the GB model in Fig. 7 were set as shown in Table VII.

The number of tank models connected to the GB model was 5000 , and each tank had a power rating of $40 \mathrm{~kW}$. The first loss of generation of $345 \mathrm{MW}$ was applied to the GB model at 90 $\mathrm{s}$ and the second loss of generation of $1237 \mathrm{MW}$ was added at 185 s. Simulation results are given in Figs. 16-18.

Fig. 16 shows the drop of grid frequency after the first and second loss of generation. Fig. 17 shows the change of power output of generators (see the left axis) and the power of tanks (see the right axis). The power consumption of tanks reduced by $20 \mathrm{MW}$ following the loss of $345 \mathrm{MW}$ generation. After the loss of 1237-MW generation, the load of tanks reduced by a further $60 \mathrm{MW}$. The final frequency was $49.22 \mathrm{~Hz}$ compared with $49.19 \mathrm{~Hz}$ experienced without the tank response. The

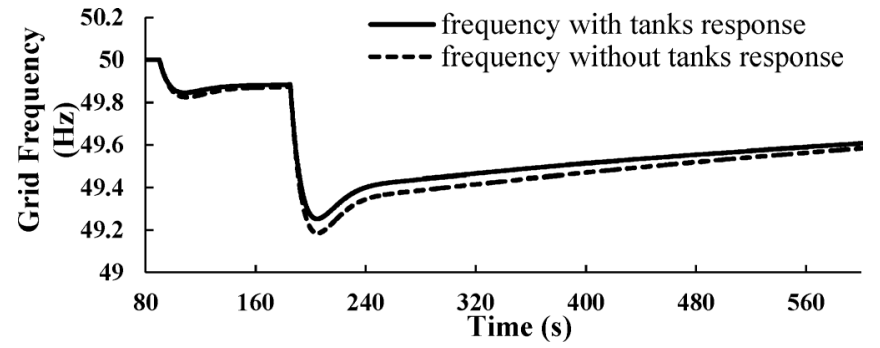

Fig. 16. Variation of grid frequency.

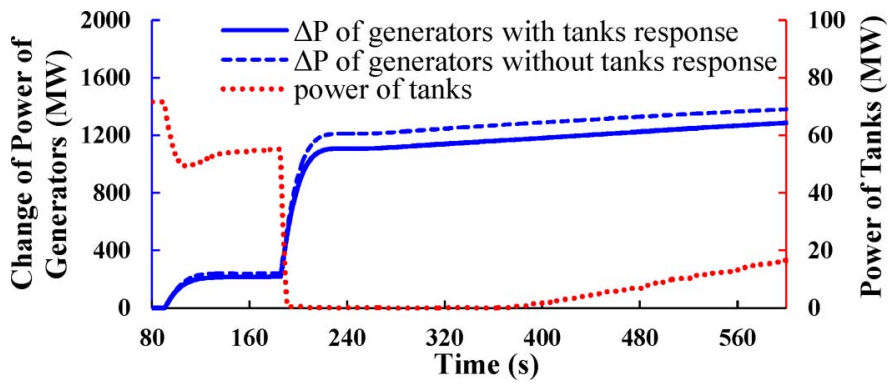

Fig. 17. Change of power output $(\Delta \mathrm{P})$ of generators and the power of tanks.

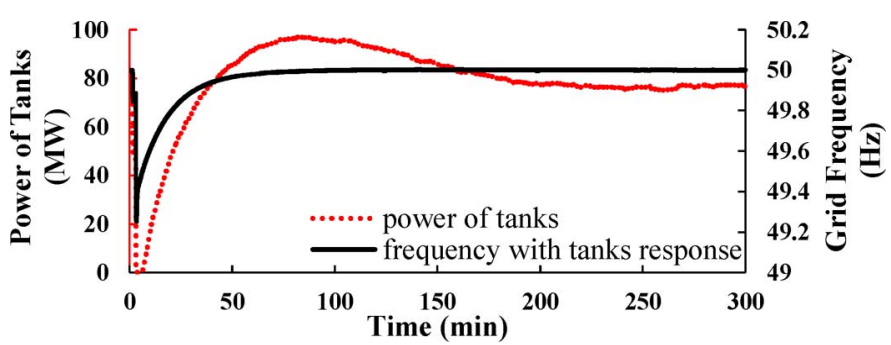

Fig. 18. Power of tanks after the drop of frequency.

change of power output of the frequency-sensitive generators also decreased.

When frequency started to recover, tanks were not reconnected before frequency returned to above $49.5 \mathrm{~Hz}$ at $380 \mathrm{~s}$. This was because the trigger frequency of tanks (in Section II) was set in the range of $49.5-50 \mathrm{~Hz}$. When frequency returned to a value higher than $49.5 \mathrm{~Hz}$, tanks were reconnected in sequence following the rise of frequency.

Fig. 18 shows the power of tanks (see the left axis) and the grid frequency (see the right axis). The lost thermal energy of tanks during the period of sustained low frequency (80 $\mathrm{s}-30 \mathrm{~min})$ was restored gradually after the incident (30-180 $\mathrm{min})$.

\section{Third Case Study}

The third case study was undertaken by connecting the tank models to a detailed whole GB transmission system model which is at present used by the GB transmission system operator, National Grid plc. The schematic diagram of the detailed GB transmission system model can be found in [19]. Twelve models representing the distribution networks are connected to the GB transmission system model. There are 11792 buses in the whole GB system model.

An aggregated tank model is connected to a $33-\mathrm{kV}$ bus-bar in each of the 12 distribution network models. The number of 
TABLE VIII

NUMBER OF TANKS IN EACH DISTRIBUTION NETWORKS

\begin{tabular}{l|r}
\hline \hline DNO1 & 2,000 \\
\hline DNO2 & 5,000 \\
\hline DNO3 & 4,000 \\
\hline DNO4 & 3,000 \\
\hline DNO5 & 2,500 \\
\hline DNO6 & 4,300 \\
\hline DNO7 & 2,300 \\
\hline DNO8 & 3,500 \\
\hline DNO9 & 3,600 \\
\hline DNO10 & 1,800 \\
\hline DNO11 & 1,080 \\
\hline DNO12 & 4,900 \\
\hline Total & 37,980 \\
\hline \hline
\end{tabular}

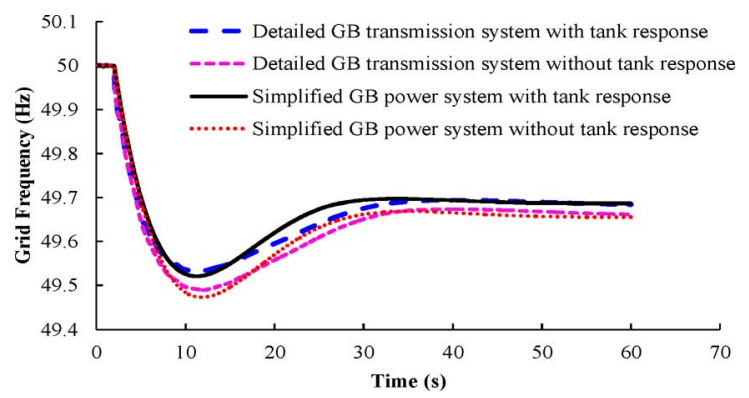

Fig. 19. Variation of grid frequency after the loss of generation.

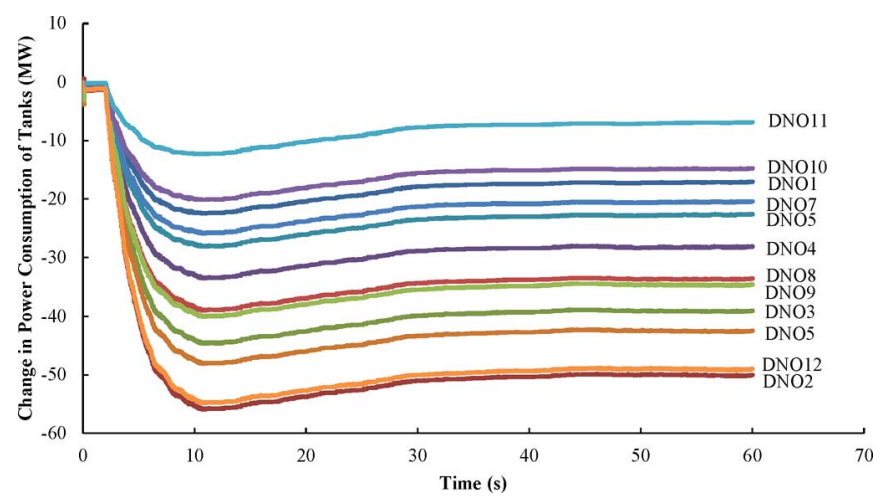

Fig. 20. Power reduction of tanks at different locations in the detailed GB transmission system model.

tanks in each distribution network is listed in Table VIII, which was obtained based on the number of electricity customers in different areas. Each tank is assumed to have a power rating of $40 \mathrm{~kW}$.

A loss of generation of $4 \mathrm{GW}$ was applied at $2 \mathrm{~s}$. System demand was approximately $53 \mathrm{GW}$. Simulations were also carried out using the simplified GB power system model as presented in Section III-B for comparison with the same number of tank models given in Table VIII being connected. Simulation results are shown in Figs. 19 and 20.

Fig. 19 shows the drop of grid frequency after the generation loss and Fig. 20 shows the changes in the power drawn by tanks at different locations. It can be seen that tanks at different locations provided frequency response in proportion to the frequency deviation. In addition, the location of tanks showed little impact on the frequency response they provided. Fig. 19 also shows that the behavior of grid frequency of the simplified GB power system model was similar to that of the detailed GB transmission system model.

\section{CONCLUSION}

A decentralized frequency controller for bitumen tanks was developed to allow the tanks to alter their power consumption in proportion to the deviations of grid frequency. Each tank has an equal opportunity to be switched on/off and respond to frequency deviations. The frequency control does not interfere with the original control and hence temperature of the tanks.

Field tests were undertaken to validate the frequency control of tanks. An aggregated model of tanks equipped with the frequency control was developed and verified against the field tests. The tank model behaved similarly to the tanks in the field tests.

The tank model was then integrated into a simplified GB power system model. Case studies showed that, following a loss of generation, the deviations of grid frequency were reduced with immediate load change of tanks. The power taken from frequency-sensitive generators was also decreased.

The load change of $72 \mathrm{MW}$ from tanks was small in the context of the GB power system. However, if such frequency control is employed on other types of loads, their contribution of reducing the frequency deviations will be considerable. The control of loads in this way will provide an effective means of frequency response service currently provided mainly by the frequency-sensitive generation. Furthermore, the faster load change following the frequency deviations will yield further benefit in the future power system where there will be a reduction of system inertia.

\section{ACKNOWLEDGMENT}

The authors would like to thank Open Energi for sharing their patented dynamic demand technology. All data created during this research are openly available from Cardiff University data archive at http://dx.doi.org/10.17035/d.2015.100102.

\section{REFERENCES}

[1] I. A. Erinmez, D. O. Bickers, G. F. Wood, and W. W. Hung, "NGC experience with frequency control in England and Wales - Provision of frequency response by generators," in Proc IEEE Power Eng. Soc. Winter Meeting, 1999, vol. 1, pp. 590-596.

[2] National Grid plc, "The Grid Code Issue 5 Revision 4," Aug. 2013 [Online]. Available: http://www.nationalgrid.com/NR/ rdonlyres/67374C36-1635-42E8-A2B8-B7B8B9AF2408/62011/ 00_GRID_CODE_FULL_I5R4.pdf

[3] National Grid plc, "Operating the Electricity Transmission Networks in 2020," Jun. 2011 [Online]. Available: http://www.nationalgrid.com/ uk/Electricity/Operating + in $+2020 /$

[4] National Grid plc, "Report of the Investigation Into the Automatic Demand Disconnection Following Multiple Generation Losses and the Demand Control Response that Occurred on the 27th May 2008," [Online]. Available: http://www.Nationalgrid.com/NR/rdonlyres/D680C70A-F73D-4484-BA54-95656534B52D/26917/PublicReportIssue1.pdf

[5] National Grid plc, "Demand Side Developments Operational Forum," Mar. 2003 [Online]. Available: http://www.nationalgrid.com/NR/ rdonlyres/96F5467A-C673-404F-9E71-4AE8ED0F5FE3/2361/demand_side_developments032003.pdf

[6] dynamicDemand, "The Technology," [Online]. Available: http://www. dynamicdemand.co.uk/the technology.htm

[7] M. Kintner-Neyer, R. Guttromson, D. Oedingen, and S. Lang, "Final report for the energy efficient and affordable small commercial and residential buildings research program, Project 3.3- Smart Load Control and Grid Friendly Appliances," Pacific Northwest Nat. Lab., 2003. 
[8] J. Kondoh, N. Lu, and D. J. Hammerstrom, "An evaluation of the water heater load potential for providing regulation service," IEEE Trans. Power Syst., vol. 26, no. 3, pp. 1309-1316, Aug. 2011.

[9] N. Lu, "An evaluation of the HVAC load potential for providing load Balancing service," IEEE Trans. Smart Grid, vol. 3, no. 9, pp. 1263-1270, 2012

[10] F. C. Schweppe, R. D. Tabors, J. L. Kirtley, H. R. Outhred, F. H. Pickel, and A. J. Cox, "Homeostatic utility control," IEEE Trans. Power App. Syst., vol. PAS-99, no. 5/6, pp. 1151-1163, May-Jun. 1980.

[11] J. A. Short, D. G. Infield, and L. L. Freris, "Stabilization of grid frequency through dynamic demand control," IEEE Trans. Power Syst., vol. 22, no. 3, pp. 1284-1293, Aug. 2007.

[12] Z. Xu, J. Ostergaard, and M. Togeby, "Demand as frequency controlled reserve," IEEE Trans. Power Syst., vol. 26, no. 3, pp. 1062-1071, Aug. 2011.

[13] G. Strbac, "Demand side management: Benefits and challenges," Energy Policy, vol. 36, pp. 4419-4426, 2008.

[14] T. Bopp, "Technical and commercial integration of distributed and renewable energy sources into existing electricity networks," Ph.D. dissertation, Dept. Electr. Electron. Eng., Univ. of Manchester, Manchester, U.K., 2006.

[15] P. Kundur, Power System Stability and Control. New York, NY, USA: McGraw-Hill, 1994, pp. 581-627.

[16] M. Cheng, J. Wu, S. Galsworthy, N. Jenkins, and W. Hung, "Availability of load to provide frequency response in the Great Britain power system," in Proc. 18th Power Syst. Computation Conf., Aug. 2014, pp. $1-7$.

[17] W. Hung, G. Ray, and G. Stein, "Frequency changes during large disturbances WG," National Grid plc [Online]. Available: http:/www.nationalgrid.com/NR/rdonlyres/D07952E0-2B58-426FB61F-C77A239D3964/5720/Meeting1Presentation.pdf

[18] J. Ekanayake, N. Jenkins, and G. Strbac, "Frequency response from wind turbines," Wind Eng., vol. 32, no. 12, pp. 573-586, 2008.

[19] National Grid plc, "ETYS 2014 Appendix A1_3 to A1_6 - GB Existing Transmission System - Schematic," Nov. 2014 [Online]. Available: http://www2.nationalgrid.com/UK/Industry-information/Futureof-Energy/Electricity-Ten-Year-Statement/

Meng Cheng received the B.Sc. degree in electrical and electronic engineering from Cardiff University, Cardiff, U.K., and North China Electric Power University, Beijing, China, in 2011, and the Ph.D. degree from Cardiff University in 2015.

She is currently a Research Associate with Cardiff University, Cardiff, U.K. Her main research interests include smart grids and dynamic demand.

Jianzhong Wu (M'06) received the Ph.D. degree in electrical engineering from Tianjin University, Tianjin, China, in 2004.

He is currently a Professor with the Institute of Energy, Cardiff University, Cardiff, U.K. His research focuses on energy infrastructure and smart grid.
Stephen J. Galsworthy received the M.Math. and Ph.D. degrees from Oxford University, Oxford, U.K., in 2004 and 2009, respectively.

He is currently a Consultant with TNO, the Dutch Organization for Applied Scientific Research, The Hague, The Netherlands, where he specializes in international consultancy work focused on smart grid projects. Prior to this he was Technology Development Manager, Open Energi, London, U.K., working on dynamic demand.

Carlos E. Ugalde-Loo (M'02) received the B.Sc. degree in electronics and communications engineering from ITESM, Monterrey, Mexico, in 2002, the M.Sc degree in electrical engineering from IPN, Mexico, in 2005, and the Ph.D. degree in electronics and electrical engineering from the University of Glasgow, Scotland, U.K., in 2009.

In 2010, he joined the School of Engineering, Cardiff University, Cardiff, U.K., where he is currently a Lecturer in electrical power systems.

Nikola Gargov received the B.Eng. degree from the Technical University of Sofia, Sofia, Bulgaria, in 2008, the M.Sc. degree from Brunel University, London, U.K., in 2009, and the Ph.D. degree from the University of Exeter, Exeter, U.K., in 2013.

He is currently with National Grid, Warwick, U.K., as a Power Systems Engineer specializing in network planning and operation.

William W. Hung received the B.Sc (Hons) degree from the University of Northumbria, Newcastle upon Tyne, U.K., in 1975, the Ph.D. degree from Loughborough University, Loughborough, U.K., in 1983, and the M.B.A. degree from Warwick University, Warwick, U.K., in 1995.

He is currently the Director of WH Power Systems Consultant Ltd, Honorary Professor at Warwick University, Warwick, U.K., and a Technical Director of a National Grid NIA project at Cardiff University, Cardiff, U.K. He was with National Grid until 2013 after 24 years of service, and his last role there was a Technical Leader responsible for system dynamic modelling, control, and monitoring.

Nick Jenkins (M'81-SM'97-F'05) received the B.Sc. degree from Southampton University, Southampton, U.K., in 1974, the M.Sc. degree from Reading University, Reading, U.K., in 1975, and the Ph.D. degree from Imperial College London, London, U.K., in 1986.

He is currently a Professor and Director, Institute of Energy, Cardiff University, Cardiff, U.K. Before moving to academia, his career included 14 years of industrial experience, of which five years were in developing countries. While at university, he has developed teaching and research activities in both electrical power engineering and renewable energy. 